\title{
EFFICACY AND SAFETY OF WEIGHT BASED INSULIN ORDER FOR BLOOD GLUCOSE CONTROL OF TYPE 2 DIABETES MELLITUS
}

\author{
Muhammad Atif Tauseef ${ }^{1}$, Muhammad Arshad ${ }^{1}$, Shah Zeb ${ }^{1}$ \\ 1. Naseer Teaching Hospital Peshawar
}

\begin{abstract}
Objective:

To determine the efficacy and safety of weight based insulin order for blood glucose control in type II diabetes mellitus
\end{abstract}

Study Design: Descriptive case series.

Place and Duration of Study:

Conducted in department of medicine, Naseer Teaching Hospital, Peshawar. From $6^{\text {th }}$ August 2013 to $5^{\text {th }}$ Feb. 2014.

\section{Methodology:}

This descriptive study was conducted in the department of medicine NTH Peshawar between $6^{\text {th }}$ august 2013 to $5^{\text {th }}$ Feb.2014. A total of 292 patients were included in study based on 5\% proportion of hypoglycemia of weight based insulin order, 95\% confidence level and 2.5\% margin of error under WHO Software for sample size determination. Patients were started on Weight Based Insulin order from day $1^{\text {st, }}$ and their blood glucose levels were checked every 6hr, by 48hrs of Weight Based Insulin Order efficacy (improvement in blood glucose level of $\geq 250 \mathrm{mg} / \mathrm{dl}$ from baseline) and safety (absence of hypoglycemic episode) were determined.

Results:

A total of 292 cases were studied in a 6 month period. The mean age of patients included in study was 59.73 \pm 7.33 and there were 173(59.2\%) males and 119(40.8\%) females. By 48hrs of Weight Based Insulin Order efficacy (improvement of blood glucose level of $250 \mathrm{mg} / \mathrm{dl}$ from baseline) was observed in 187(64.1\%) while remaining 105(35.9\%) were not efficacious, safety (absence of hypoglycemic episode) was observed in 272(93.2\%) while remaining 20(6.8) were unsafe (with episode of hypoglycemia).

\section{Conclusion:}

Weight Based Insulin Order is effective and safe in type2 DM and they should be used routinely in hyperglycemic patients that are hospitalized.

Key Words: Diabetes Mellitus, Weight Based Insulin Order.

\section{INTRODUCTION}

Diabetes Mellitus is the commonest one of widespread disease. It is the emerging

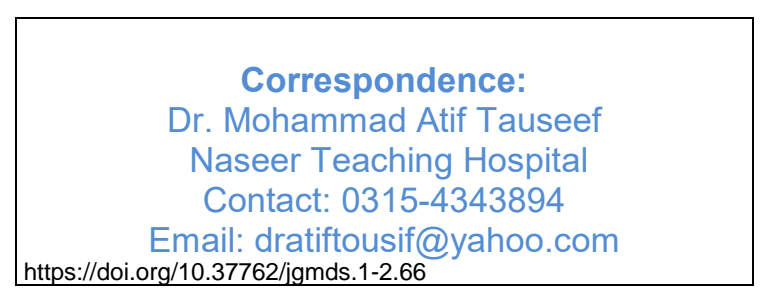
pandemic. A recent survey estimated that $22 \%$ of all hospital inpatient days were incurred by people with diabetes and that hospital inpatient care accounted for half of the $\$ 174$ billion total US medical expenditures for this disease. These findings are due, in part, to the continued expansion of the worldwide epidemic of type 2 diabetes. In the United States alone, with an overall prevalence of 23.6 million people ( $7.8 \%$ of the population) ${ }^{1}$. Diabetes is a chronic illness that requires continuing medical care and ongoing patient self management education and support to prevent acute complications and to decrease the risk of long term complications $^{2}$. Optimum glucose control has been the aim and dream of the 
physician especially for the admitted patients, hyperglycemia in hospitalized patients, irrespective of its cause, is unequivocally associated with adverse outcomes. As uncontrolled glucose levels are associated with increase complications, prolong stay, more infections and increase health $\operatorname{cost}^{3}$. A 2009 consensus statement on inpatient glycemic control management from American association of clinical endocrinologists and ADA calls for scheduled s/c insulin Administration with weight based insulin order that promotes best outcomes. It discourages both prolong use of Sliding Scale Insulin Order as the sole regimen and use of non insulin agents for most hospitalized patients ${ }^{4}$.

The term "weight based insulin order (WBIO)" which refers to the insulin order in which insulin Dose is calculated based on patients weight i.e. 0.5 units per $\mathrm{kg}$ body weight half of this is given as long acting (NPH) at bed time as basal bolus insulin and the remaining half is divided into three to cover meals as short acting insulin ${ }^{5}$. Weight based insulin order is individualized for each patient, while in Sliding scale insulin order a patient weighting $90 \mathrm{~kg}$ would receive the same amount of insulin as one who weighs $60 \mathrm{~kg}$, the first patient may not receive enough insulin to correct Hyperglycemia, while the $2^{\text {nd }}$ get too much insulin and suffer Hypoglycemia so weight based insulin order decreases length of stay at hospital, improved patients outcomes fewer hypoglycemic episode $^{6}$. Prolonged therapy with sliding scale insulin as the sole regimen is ineffective in the majority of patients and potentially dangerous in those with type 1 diabetes $^{7-10}$.

According to a study weight based insulin orders achieve efficacy in (58\%) of cases, and in (5\%) of cases episodes of hypoglycemia occurred while sliding scale insulin orders achieves efficacy in $(44 \%)$ of cases and in $(6 \%)$ of cases hypoglycemic episodes occurred ${ }^{5}$. RATIONALE: Rationale of the study is to determine the efficacy and safety of weight based insulin order in type $2 \mathrm{DM}$. The rationale behind doing this study is to determine the local statistics of efficacy and safety of WBIO in terms of blood glucose control and hypoglycemic episodes. The results of this study will be shared with other local health professionals and if efficacy and safety is found to be significantly high, we will recommend its routine use for patients with type 2DM and even if the efficacy and safety is found to be low, we will recommend more research work on WBIO before giving recommendations for future utilizations of WBIO.

\section{METHODOLOGY}

Approval of hospital ethical committee was taken. All patients meeting the inclusion criteria(patients with type II DM having fasting blood glucose of more than $400 \mathrm{mg} / \mathrm{dl}$ ) were included in the study through OPD and ER department and were admitted in the medical ward for further evaluation. Exclusion criteria was patients with type $1 \mathrm{DM}$, critically ill patients, fasting blood glucose less than $400 \mathrm{mg} / \mathrm{dl}$ and age less than 45 years. The purpose and benefits of the study were explained to all patients and their relatives were assured that study is done purely for data publication and research purpose; they were explained about the possible risks involved and when agreed upon an informed written consent was taken from all patients.

All patients were given WBIO as per plan [0.5 units $/ \mathrm{kg}$ wt total insulin/day, $1 / 2$ given at bedtime as long acting (NPH), $1 / 2$ was split in 3 portions to be given with meals(short acting)] and were kept in study for 48 hours in that period blood glucose levels were checked every six hours to detect efficacy and safety of the WBIO. Efficacy was labeled if at $48^{\text {th }}$ hours that patient's blood glucose drops $250 \mathrm{mg} / \mathrm{dl}$ from baseline and safety by absence of any episode of hypoglycemia by $48^{\text {th }}$ hour. All the above mentioned information was recorded in a pre designed proforma. Strictly exclusion criteria was ( patients with type $1 \mathrm{DM}$, critically ill patients, fasting blood glucose less than 400mg/dl and age less than 45 years )followed to control confounders and bias in the study results. All the laboratory investigations were done by single consultant pathologist having minimum of five years of experience and by using standard and uniform measuring equipments in the laboratory. All the 
data was stored and analyzed in SPSS version 10. Frequency and percentages were calculated for categorical variables like Gender, Hypoglycemic episodes, Efficacy and safety. Mean \pm S.D was calculated for continuous variables like age, baseline and after 48 hours blood glucose level. Efficacy and safety were stratified among the age, gender and baseline blood glucose level to see the effect modification. All the results were presented as tables and graphs

\section{RESULTS}

A total of 292 cases were studied. Patient with different ages were distributed in three groups, there were $81(28 \%)$ cases in age range of $45-55$ years, while $130(44 \%)$ cases in $55-65$ years and $81(28 \%)$ cases in $65+$ years(TABLE: 3 ). Mean and standard deviation for age calculated was $59.73 \pm 7.33$. There were $173(59.2 \%)$ males and $119(40.8 \%)$ females of the total Patient with different baseline blood glucose level included in sample were distributed in three groups, there were $110(37.3 \%)$ cases in baseline blood glucose range of $400-450 \mathrm{mgj} / \mathrm{dl}$, while $84(28.8 \%)$ cases in $450-500 \mathrm{mg} / \mathrm{dl}$ and $98(33.5 \%)$ cases in $500+\mathrm{mg} / \mathrm{dl}$. Mean and standard deviation for baseline blood glucose level calculated was $470.07 \pm 41.18 \mathrm{mg} / \mathrm{dl}($ TABLE: 4$)$. Patients with different blood glucose after 48hours of WBIO were distributed in three groups, there were $96(25 \%)$ cases in 60 $150 \mathrm{mg} / \mathrm{dl}$, while $96(28.7 \%)$ in $150-250 \mathrm{mg} / \mathrm{dl}$ and $100(46.3 \%)$ cases in $250+\mathrm{mg} / \mathrm{dl}$. Mean and standard for blood glucose after 48 hours calculated was $199.43 \pm 77.75 \mathrm{mg} / \mathrm{dl}($ TABLE: 5$)$.

Efficacy (improvement in blood glucose of $\geq 250 \mathrm{mg} / \mathrm{dl}$ from baseline) was found to be in $187(64.1 \%)$ cases while remaining 105(35.9\%) were not efficacious out of total of 292 cases (TABLE: 6). Safety (absence of hypoglycemic episode after 48hours of WBIO) was found to be in $270(93.2 \%)$ cases while remaining $20(6.8 \%)$ cases were unsafe, out of total of 292cases(TABLE: 7).This efficacy and safety was stratified among age groups, gender and baseline blood glucose and following results were found. When efficacy was stratified for different age groups, efficacy was noted in $60(74 \%)$ cases in age range of $45-55$ years while $90(69 \%)$ in 55-65years and $37(45.7 \%)$ cases in 65+years(TABLE: 8).When efficacy was stratified for gender, efficacy was noted in $104(60.1 \%)$ cases of males while $83(69.7 \%)$ of females(TABLE: 9$)$. when efficacy was stratified for baseline blood sugar efficacy was noted in $88(80 \%)$ in $400-450 \mathrm{mg} / \mathrm{dl}$, while $54(64.3 \%)$ in 450 $500 \mathrm{mg} / \mathrm{dl}$ and $45(45.9 \%)$ of cases in $500+\mathrm{mg} / \mathrm{dl}$ range(TABLE: 10$)$. Safety when stratified for different age groups safety was noted in 78(96.3\%)cases in age range of 45-55years, while $123(94.6 \%)$ cases in 55-65years and $71(87.6 \%)$ in $65+$ years(TABLE: 11$)$. when safety was stratified for gender safety was noted in $165(95.4 \%)$ males, while $107(89.9 \%)$ of females(TABLE: 12).When safety was stratified for Baseline Blood Glucose it was noted in $98(89 \%)$ cases in 400 $450 \mathrm{mg} / \mathrm{dl}$ while $77(91.7 \%)$ cases in $450-500 \mathrm{mg} / \mathrm{dol}$ and $97(98.9 \%)$ cases in 500+mg/dl(TABLE: 13$)$

Table-3. Age wise distribution of samples $\mathrm{n}=\mathbf{2 9 2}$

\begin{tabular}{|c|c|c|}
\hline $\begin{array}{c}\text { Age ranges } \\
\text { (years) }\end{array}$ & Frequency & Percentage \\
\hline $45-55$ & 81 & $28 \%$ \\
\hline $55-65$ & 130 & $44 \%$ \\
\hline $65+$ & 81 & $28 \%$ \\
\hline Total & 292 & $100 \%$ \\
\hline $\begin{array}{c}\text { Mean Age } \pm \\
\text { SD }\end{array}$ & $59.73 \pm 7.33$ \\
\hline
\end{tabular}




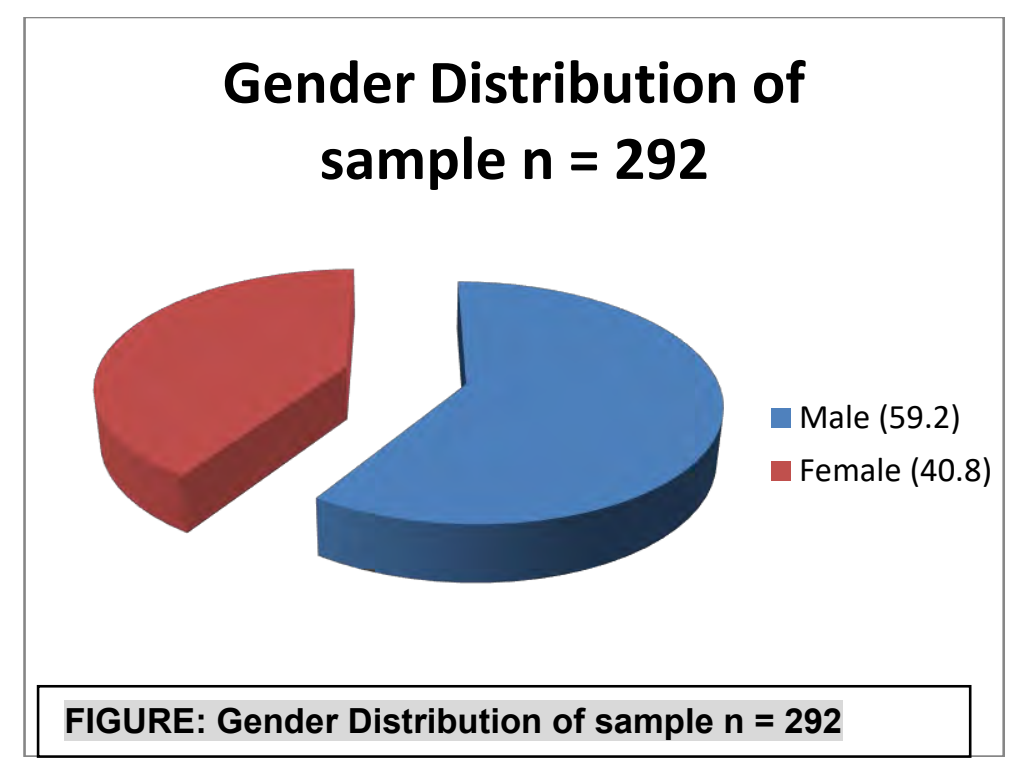

Table-4. Baseline Blood glucose wise distribution of sample $\mathrm{n}=\mathbf{2 9 2}$

\begin{tabular}{|l|l|l|}
\hline \multicolumn{1}{|c|}{$\begin{array}{c}\text { Baseline Blood Glucose } \\
\text { In }(\mathbf{m g} / \mathbf{d})\end{array}$} & Frequency & Percentage \\
\hline $400-450$ & 110 & $37.7 \%$ \\
\hline $450-500$ & 84 & $28.8 \%$ \\
\hline $500+$ & 98 & $33.5 \%$ \\
\hline Total & 292 & $100 \%$ \\
\hline Mean \pm SD of Baseline blood glucose & $470 \pm 41.18$ \\
\hline
\end{tabular}

Table-5. Blood Glucose after 48hours wise distribution of sample $n=292$

\begin{tabular}{|l|l|l|}
\hline Blood Glucose after 48hours in (mg/dl) & Frequency & Percentage \\
\hline $60-150$ & 96 & $25 \%$ \\
\hline $150-250$ & 96 & $28.7 \%$ \\
\hline $250+$ & 100 & $46.3 \%$ \\
\hline Total & 292 & $100 \%$ \\
\hline $\begin{array}{l}\text { Mean } \pm \text { SD of Blood Glucose after } \\
\text { 48hours }\end{array}$ & \multicolumn{2}{|c|}{$199.43 \pm 77.75$} \\
\hline
\end{tabular}

Table-6. Efficacies

\begin{tabular}{|l|l|l|}
\hline Efficacy & Frequency & Percentage \\
\hline Yes & 187 & $64.1 \%$ \\
\hline No & 105 & $35.9 \%$ \\
\hline
\end{tabular}

Table-7. Safety

\begin{tabular}{|l|l|l|}
\hline Safety & Frequency & Percentage \\
\hline Yes & 272 & $93.2 \%$ \\
\hline No & 20 & $6.8 \%$ \\
\hline
\end{tabular}

Table-8. Efficacy Vs Age Groups

\begin{tabular}{|l|l|l|l|l|}
\hline Efficacy & $\begin{array}{l}\text { Age group 1 } \\
\text { 45-55years }\end{array}$ & $\begin{array}{l}\text { Group 2 } \\
\text { 55-65years }\end{array}$ & $\begin{array}{l}\text { Group 3 } \\
\text { 65+years }\end{array}$ & Total \\
\hline Yes & $60(74 \%)$ & $90(69 \%)$ & $37(45.7 \%)$ & $187(64.1 \%)$ \\
\hline No & $21(26 \%)$ & $40(31 \%)$ & $43(53 \%)$ & $105(35.9 \%)$ \\
\hline
\end{tabular}


Table-9. Efficacy Vs Gender

\begin{tabular}{|l|l|l|l|}
\hline Efficacy & Males & Females & Total \\
\hline Yes & $104(60.1 \%)$ & $83(69.7 \%)$ & $187(64.1 \%)$ \\
\hline No & $69(39.9 \%)$ & $36(30.3 \%)$ & $105(35.9 \%)$ \\
\hline
\end{tabular}

Table-10. Efficacy Vs Baseline Blood Glucose

\begin{tabular}{|l|l|l|l|l|}
\hline Efficacy & $\begin{array}{l}\text { Group1 } \\
\text { 400-450mg/dl }\end{array}$ & $\begin{array}{l}\text { Group2 } \\
\mathbf{4 5 0 - 5 0 0 m g / d l}\end{array}$ & $\begin{array}{l}\text { Group3 } \\
\mathbf{5 0 0 + m g / d l}\end{array}$ & Total \\
\hline Yes & $88(80 \%)$ & $54(64.3 \%)$ & $45(45.9 \%)$ & $187(64.1 \%)$ \\
\hline No & $22(20 \%)$ & $30(35.7 \%)$ & $53(54.1 \%)$ & $105(35.9 \%)$ \\
\hline
\end{tabular}

Table-11. Safety Vs Age Groups

\begin{tabular}{|l|l|l|l|l|}
\hline Safety & $\begin{array}{l}\text { Group1 } \\
\text { 45-55 years }\end{array}$ & $\begin{array}{l}\text { Group2 } \\
\mathbf{5 5 - 6 5} \text { years }\end{array}$ & $\begin{array}{l}\text { Group3 } \\
\text { 65+years }\end{array}$ & Total \\
\hline Yes & $\mathbf{7 8}(96.3 \%)$ & $123(94.6 \%)$ & $71(87.6 \%)$ & $272(93.2 \%)$ \\
\hline No & $3(3.7 \%)$ & $7(5.4 \%)$ & $10(12.4 \%)$ & $20(6.8 \%)$ \\
\hline
\end{tabular}

Table-12. Safety Vs Genter

\begin{tabular}{|l|l|l|l|}
\hline Safety & Male & Female & Total \\
\hline Yes & $165(95.4 \%)$ & $107(89.9 \%)$ & $272(93.2 \%)$ \\
\hline No & $8(4.6 \%)$ & $12(10.1 \%)$ & $20(6.8 \%)$ \\
\hline
\end{tabular}

Table-13. Safety Vs Baseline Blood Glucose

\begin{tabular}{|l|l|l|l|l|}
\hline Safety & $\begin{array}{l}\text { Group1 } \\
\text { 400-450mg/dl }\end{array}$ & $\begin{array}{l}\text { Group2 } \\
\mathbf{4 5 0 - 5 0 0 m g / d l}\end{array}$ & $\begin{array}{l}\text { Group3 } \\
\mathbf{5 0 0 + m g / d l}\end{array}$ & Total \\
\hline Yes & $98(89 \%)$ & $77(91.7 \%)$ & $97(98.9 \%)$ & $272(93.2 \%)$ \\
\hline No & $12(11 \%)$ & $7(8.3 \%)$ & $1(1.02 \%)$ & $20(6.8 \%)$ \\
\hline
\end{tabular}

\section{DISSCUSSION}

To date no clear evidence exists to determin optimal glycemic targets in non-critically ill patients. However experts agree that better glycemic control in hospitalized patients is warrented $^{11 \text {, }}$ 12. There is increasing evidence demonstrating negative consequences and poor clinical outcomes associated with untreated hyperglycemia in hospitalized patients hyperglycemia has been correlated to a number of negative outcomes at cellular level including immune suppression, endothelial dysfunction, increase oxidative stress and thrombosis ${ }^{13}$. Insulin is agent of choice for easy titration and rapid achievement of glycemic control is hospitalized patients ${ }^{14,}$ among the many insulin management systems that have been developed none has been as widely used as sliding scale, despite its acceptance by physicious throughout the world, however there is little eveidence of sliding scale efficacy ${ }^{15-16}$. A number of studies have focused on potential problems associated with sliding scale primarily related to the" roller coaster" blood glucose levels that often result. It is concluded that fluctuating blood glucose levels are more harmful physiologically that levels that are continuously elevated even when elevations are mild ${ }^{17}$.

The American diabetes association "ADA" which publishes standards of care for diabetes annually in its diabetes care journal has discouraged sliding scale insulin. A 2009 consensus statement on inpatient glycemic control management calls for scheduled weight based insulin orders, an approach that promotes best outcomes, it discourages both prolong use of SSI as sole. Regimen and use of non insulin agents for most hospitalized patients ${ }^{18}$. In my study that included 292 patients efficacy (improvement in blood glucose level of $\geq 250 \mathrm{mg} / \mathrm{dl}$ from base line) was seen in $187(64.1 \%)$ of cases while hypoglycemic episodes were noted in $20(6.8 \%)$ of cases. It definitely 
highlights the efficacy of WBIO that is already a published fact. While hypoglycemic episodes that are definitely a concern in case of WBIO though in published data no significant difference in hypoglycemic episodes is noted in those on SSI or $\mathrm{WBIO}^{19}$.

Similar results are demonstrated by a study published in diabetes care of ADA IN 2005, a total of 88 patients were assigned WBIO. It was observed that WBIO were efficacious in $(65.1 \%)$ of cases. In this study blood glucose $<60 \mathrm{mg} / \mathrm{dl}$ was observed in $(3.6 \%)$ of cases in patients $\mathrm{WBIO}^{20}$. Here we can see the difference in terms of hypoglycemic episodes in my study and that quoted and this is probably related to two factors $1^{\text {st }}$ study quoted used reference value for hypoglycemic $\leq 60 \mathrm{mg} / \mathrm{dl}$ while I have used $\leq 70 \mathrm{mg} / \mathrm{dl} 2^{\text {nd }}$ my exclusion criteria did not include patient with renal impairment that results in hypoglycemic episode in significant number of cases.

In another study published in journal of pharmacy practice "Oct 2009130 patients were randomly assigned to SSIO and WBIO with similar baseline characteristics WBIO showed efficacy in $66 \%$ of cases while SSIO in $38 \%$ of cases and there was no significant difference in terms of hypoglycemia ${ }^{21}$. In study published in journal of king Edward Medical University Lahore efficacy of Weight based insulin order was found to be (58\%) and hypoglycemic episodes occurred in (5\%) of cases $^{22}$. There were some limitations in my study in terms of exclusion criteria that should have included patients with renal impairment, patients on medications that can affect glycemic control e.g. corticosteroids and systemic illnesses and above all dietary factors so that efficacy / safety would be determind with more confidence and generalization factors would be satisfied.I recommend more studies on weight based insulin order with head on comparision with sliding scale with similar characteristics of patients,so that efficacy and safety of weight based insulin order could be appreciated with more confidence. I must say that fundamental principle to achieve glycemic control we should avoid "one size fits all" mentality, no evidence exists to support use of SSI for effective glycemic control the rabbit 2 trial clearly provides evidence in support of WBIO to more effectively achieve glycemic control ${ }^{23}$

\section{CONCLUSION}

I conclude that WBIO are more effective and safe for glycemic control in patients of type 2 DM who are hospitalized. Their action mimics the physiological action of body to control blood glucose level. They are easy to use and just need to measure patients weight on admission. They should be used routinely for hyperglycemia in hospitalized patients as evidences support their use.

\section{REFRENCES}

1. American Diabetes Association. Economic costs of diabetes in the U.S. in 2007 2008;31:596-615.

2. American Diabetes Association. Standards of Medical Care in Diabetes. 2010;33(1):553.

3. Kosiborod M, Inzucchi SE, Goyal A. The relationship between spontaneous and iatrogenic hypoglycemia and mortality in patients hospitalized with acute myocardial infarction [abstract]. Circulation.2008;118(suppl):S1109.

4. Young JD Bauser, R; Brady, B; Eleyj, S. Controlling blood glucose levels in hospital patients: Current recommendations. 2009;6(5):12.

5. Salam, TU, Haque IU., Hussain M., Iqbal W., Comparative analysis between weight based insulin order and sliding scale insulin order. Annals 2009;15(2):65. 
6. Hirsch IB, Sliding scale insulin- Time to stop sliding, JAMA. 2009;301:213.

7. Umpierrez GE, Palacio A, Smiley D. Sliding scale insulin use: myth or insanity? Am J Med. 2007;120:563.

8. Korytkowski MT, Salata RJ, Koerbel GL, Insulin therapy and glycemic control in hospitalized patients with diabetes during enteral nutrition therapy; a randomized controlled clinical trial. 2009;32:594.

9. Schnipper JL, Barsky EE, Shaykevich S, Fitzmaurice G, Pendergrass ML. Inpatient management of diabetes and hyperglycemia among general medicine patients at a large teaching hospital. $J$ Hosp Med. 2006;1:145

10. Umpierrez GE. Basal versus sliding-scale regular insulin in hospitalized patients with hyperglycemia during enteral nutrition therapy. 2009;32:751.

11. Umipierrez, RABBIT 2 Trial, 2007;30:2181.

12. Standards of medical carein diabetes2010.American diabetes association .2010;33:S16-2

13. Standards of medical care in diabetes2010.American diabetes association.2010;33:S25-7

14. Clement, S Braithwaite, SSMagee,Mfet al,for the American diabetes association diabetes in hospitals writing commmittee.Management of diabetes and hyperglycemia in hospitals.Diabetes care.2004;01:553-91

15. Jolobe, O.The use of sliding scale also needs to be reviewed.QJM.2008;01:593-94.

16. .Queale WS, Seidler AJ,Brancati FL.Glycemic control and sliding scale insulin use in medical in patients with diabetes mellitus. Arch Intern Med.2011;50:545-52.

17. Standards of medical care in diabetes 2010.diabetes care.2010;33:S20-30.

18. Standards of medical care in diabetes 2010.diabetes care.2010;33:S20-30

19. Deyoung J,Bauer R,Brady C.Controlling blood glucose levels in hospital patients: current recommendations. American nurse today.2011;6:12-14

20. Daniel J,Rubin MD, et al.Weight based insulin dose related hypoglycemia in hospitalized patients with diabetes.Diabetes care.2011;34:1723-27

21. Baldwin D, Macnutt $R$ et al. Eliminating inpatient sliding scale insulin. Diabetes care.2005;28:1008-11

22. Salam, TU, Haque IU., Hussain M., Iqbal W., Comparative analysis between weight based insulin order and sliding scale insulin order. Annals 2009;15(2):65.

23. Queale WS, Seidler AJ, Brancati FL: Glycemic control and sliding scale insulin use in medical in patients with diabetes mellitus. Arch Intern Med. 1997 157:545-552,

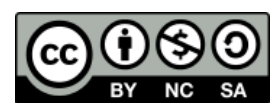

LICENSE: JGMDS publishes its articles under a Creative Commons Attribution Non-Commercial Share-Alike license (CC-BY-NC-SA 4.0) COPYRIGHTS: Authors retain the rights without any restrictions to freely download, print, share and disseminate the article for any lawful purpose. It includes scholarly networks such as Research Gate, Google Scholar, LinkedIn, Academia.edu, Twitter, and other academic or professional networking sites. 